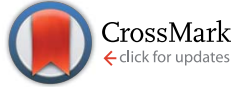

Cite this: RSC Adv., 2017, 7, 12185
Received 14th January 2017 Accepted 7th February 2017

DOI: $10.1039 / c 7 r a 00588 a$

rsc.li/rsc-advances

\section{Accumulation of camptothecin and 10- hydroxycamptothecin and the transcriptional expression of camptothecin biosynthetic genes in Camptotheca acuminata cambial meristematic and dedifferentiated cells}

\begin{abstract}
Yuhua Zhang, ${ }^{\text {abc }}$ Keming Jiang, ${ }^{a}$ Degang Qing, ${ }^{d}$ Bing Huang, ${ }^{a}$ Jiayi Jiang, ${ }^{a}$ Shumei Wang ${ }^{\star b c}$ and Chunyan Yan*a

Camptotheca acuminata Decne (Nyssaceae) is a major natural source of the anticancer drug camptothecin (CPT) and its derivatives. The leaves and stems are two of the main regions that accumulate CPT in C. acuminata. In this study, we successfully isolated cambial meristematic cells (CMCs) and dedifferentiated cells (DDCs) from C. acuminata stems and leaves, identified their characteristic features using micrograph analysis, and assessed their hypersensitivity to $\gamma$-irradiation and zeocin. The growth and kinetics curves of CMCs and DDCs were also studied. Furthermore, the accumulation of CPT and 10-hydroxycamptothecin (HCPT)-a more potent and less toxic CPT derivative-was assessed by liquid chromatography, and the transcriptional levels of nine genes encoding key enzymes involved in CPT and HCPT biosynthesis was assessed using quantitative real-time polymerase chain reaction (PCR) in CMCs and DDCs. The results showed that CMCs induced were particularly hypersensitive to $\gamma$-irradiation and zeocin and presented with abundant and small vacuoles, whereas DDCs were not. The above morphological and physiological characteristics of CMCs were consistent with previous reports. $B_{5}$ medium was determined as the best growth medium for CMCs and DDCs. The accumulation of CPT and HCPT was higher in CMCs than DDCs, and the expression of IPI, G1OH, ASA1, TSB, TDC1, TDC2, and STR was significantly upregulated in CMCs compared with DDCs; HMGR2 and HMGR3 were downregulated in CMCs. We speculate that the high accumulation of CPT and HCPT in CMCs was due to the upregulation of these seven genes.
\end{abstract}

\section{Introduction}

Camptotheca acuminata Decne belongs to the family of Nyssaceae and genus Camptotheca, and can produce camptothecin (CPT). ${ }^{1}$ CPT is a terpenoid indole alkaloid (TIA) that exhibits anti-cancer activity by inhibiting DNA topoisomerase I to kill cancer cells. ${ }^{2}$ However, CPT was not directly used in clinical treatment because of negligible water solubility and severe side effects according to a previous report. ${ }^{3}$ Conversely, 10-hydroxycamptothecin (HCPT) has been used for clinical research and was approved by the State Food and Drug Administration (SFDA) of China in 2002. In addition, CPT and HCPT are

\footnotetext{
${ }^{a}$ School of Pharmacy, Guangdong Pharmaceutical University, Guangzhou 510006, China. E-mail: ycybridge@163.com; Fax: +86-20-39352052; Tel: +86-20-39352052

${ }^{b}$ Key Laboratory of Digital Quality Evaluation of Chinese Materia Medica of State Administration of TCM, P. R. China

${ }^{c}$ Engineering \& Technology Research Center for Chinese Materia Medica Quality of the Universities of Guangdong Province, China

${ }^{d}$ Xinjiang Institute of Chinese Materia Medica and Ethnodrug, Urumqi 830002, China
}

chemical precursors of anticancer drugs such as topotecan and irinotecan, which were approved for the treatment of cervical cancer, ovarian cancer, small-cell lung cancer, and metastatic colorectal cancer by the United States Food and Drug Administration (FDA) in $1994 .{ }^{4}$ Practically, soil-grown C. acuminata are not only restricted by limited natural resources and the environment, but also produce only $0.2-5.0 \mathrm{mg} \mathrm{g}^{-1}$ dry-weight (DW) CPT in the whole plant and 2-90 $\mathrm{\mu g} \mathrm{g}^{-1}$ DW HCPT in the bark. This illustrates a serious resource crisis that should be alleviated using various approaches to identify alternative sources of CPT and HCPT. ${ }^{5}$ Sakato et al. first performed studies of C. acuminata cell culture, which produced $2.5 \mu \mathrm{g} \mathrm{g}^{-1} \mathrm{DW} \mathrm{CPT}^{6}$ Callus cultures of C. acuminata produced 1-2 $\mathrm{mg} \mathrm{g}^{-1}$ DW CPT and $80-100 \mu \mathrm{g} \mathrm{g}^{-1}$ DW HCPT. ${ }^{7,8}$ Later, some studies were performed to improve CPT production in C. acuminata. C. acuminata seedlings treated with elicitors such as abscisic acid (ABA), methyl jasmonate (MeJA), and salicylic acid (SA) produced 1.33$1.81 \mathrm{mg} \mathrm{g}^{-1}$ DW CPT and 2.25-2.60 $\mathrm{mg} \mathrm{g}^{-1}$ DW HCPT. ${ }^{9}$ Hairy roots of C. acuminata induced by Agrobacterium rhizogenes 
produced 1.0-1.2 $\mathrm{mg} \mathrm{g}^{-1}$ DW CPT and 0.15-0.31 $\mathrm{mg} \mathrm{g}^{-1} \mathrm{DW}$ HCPT. , $^{3,10,11}$

Several attempts have been made to improve the production of CPT, as mentioned above. However, no relevant studies of cultured cambial meristematic cells (CMCs) from C. acuminata have been reported. CMCs are innately undifferentiated cells located in the meristems of plants; they circumvent the dedifferentiation process and serve as the origin of plant vitality. ${ }^{12,13}$ CMCs are not negatively restricted by the source of the plant, the location, the season of harvest, and the prevailing environmental conditions; therefore, they alleviate the pressure on limited wild plant resources. ${ }^{12}$ Compared with dedifferentiated cells (DDCs) suspension cultures, CMCs suspension cultures can tolerate shear stress and thereby avoid cell aggregation in air-lift bioreactors for small or large-scale cultures because of the presence of small, abundant vacuoles within each CMC; they can also maintain a stable constant growth rate on an industrial scale. ${ }^{\mathbf{1 3 - 1 5}}$ CMCs can also secrete more natural products into the medium than DDCs. For example, the CMCs of Taxus cuspidata secrete $102 \mathrm{mg} \mathrm{kg}^{-1}$ fresh cell weight paclitaxel after culture for 10 days, whereas DDCs induced from T. cuspidata secrete just $23 \mathrm{mg} \mathrm{kg}^{-1}$ and $39 \mathrm{mg} \mathrm{kg}^{-1}$, respectively. ${ }^{13}$ Accordingly, CMCs are not only completely suitable for use in industrial production but also yield natural plant products.

In this study, C. acuminate CMCs were induced for the first time, and their morphological and physiological characteristics were consistent with CMCs previously reported..$^{13}$ We then evaluated the accumulation of CPT and HCPT by liquid chromatography (HPLC) and investigated the expression of nine genes in CMCs and DDCs from C. acuminate using quantitative real-time PCR (qRT-PCR). Our results are expected to provide a new promising culture method to improve the content of CPT and its derivatives and thereby develop a sustainable method of obtaining CPT and HCPT in the future.

\section{Results and discussion}

\section{Induction of CMCs and DDCs}

For CMCs, cambium, phloem, cortex, and epidermal stem tissues were peeled off from the xylem and laid on MS medium (Fig. 1A). After 10 days, the cambium started to present evident cell division. However, the phloem, cortex, and epidermis started to exhibit cell division by dedifferentiation by 21 days. After 60 days, compared with dim and irregular cells in phloem, cortex, and epidermal (black arrow), there were some white and loose proliferating cells in the cambium, which were CMCs (red arrow), and a visible split was observed between them (Fig. 1B). A pair of tweezers was used to gently separate the CMCs from the dim and irregular cells in the phloem, cortex, and epidermis. And the CMCs and dim and irregular cells were transferred to Murashige and Skoog (MS) medium supplemented with $0.1 \mathrm{mg} \mathrm{L}{ }^{-1}$ 2,4-dichlorophenoxyacetic acid (2,4-D), $0.1 \mathrm{mg} \mathrm{L}^{-1}$ kinetin (KT), and $0.1 \mathrm{mg} \mathrm{L}^{-1}$ naphthalene-acetic acid (NAA). The CMCs of a variety of plant species, including T. cuspidate, Panax ginseng, Ginkao biloba, and Solanum lycopersicon, have been obtained using the above technology. ${ }^{13}$ After subculture seven times, the phloem, cortex, and epidermal

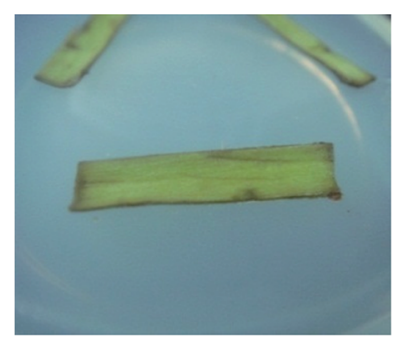

A

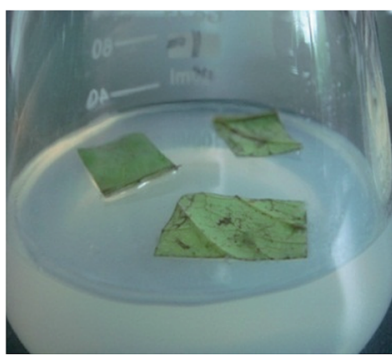

$\mathrm{C}$

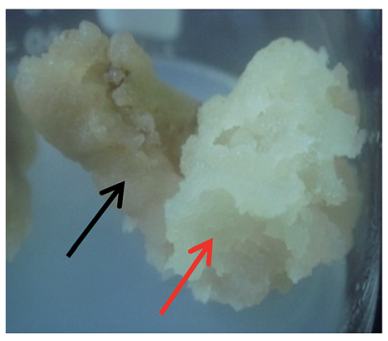

B

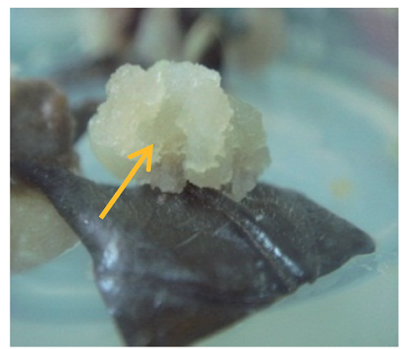

$\mathrm{D}$
Fig. 1 The induction and isolation of CMCs and DDCs from C. acuminata. (A) Cambium, phloem, cortex, and epidermal tissues from $C$. acuminata were laid on solid MS medium. (B) There was a visible split between CMCs (red arrow) and DDCs (black arrow). (C) C. acuminata leaves were laid on MS medium. (D) A mass of DDCs (yellow arrow) proliferated from the leaves.

cultures were brown and dead. In contrast, the CMCs were in good condition.

For DDCs, wounded leaves were laid on MS medium (Fig. 1C), and cell division appeared in the wounds by dedifferentiation to produce many proliferating cell masses. After 65 days, the actively growing cells were gently separated from the explants and cultured in new MS medium supplemented with $0.1 \mathrm{mg} \mathrm{L}^{-1}$ 2,4-D, $0.1 \mathrm{mg} \mathrm{L}^{-1} \mathrm{KT}$, and $0.1 \mathrm{mg} \mathrm{L}^{-1}$ NAA (Fig. 1D, yellow arrow).

\section{Identification of CMCs and DDCs}

Observed under an optical microscope, single CMC presented with abundant and small vacuoles, which is the notable characteristic feature of CMCs (Fig. 2A) ${ }^{12}$ However, single DDC just had a large vacuole (Fig. 2B). Treating with $0.1 \%$ neutral red stained the vacuoles red, there were abundant and small red vacuoles in single CMC (Fig. 2C) compared with a large red vacuole in single DDC (Fig. 2D). The above properties of the CMCs obtained from $C$. acuminata are characteristic of cambium stem cells. ${ }^{13,15}$

CMCs and DDCs were observed and photographed under a fluorescent inverted microscope after treatment with different doses of $\gamma$-irradiation and incubation for $24 \mathrm{~h}$ in the dark. Thereafter, images were processed by Adobe Photoshop software (Fig. 3A1-A3 and B1-B3). Fig. 4C shows that the cell death rate was significantly higher in CMCs than DDCs after treatment with different doses of $\gamma$-irradiation $(P<0.05)$. After incubation for $24 \mathrm{~h}$ in the dark, the cell death rate of CMCs gradually increased with increasing doses of $\gamma$-irradiation 


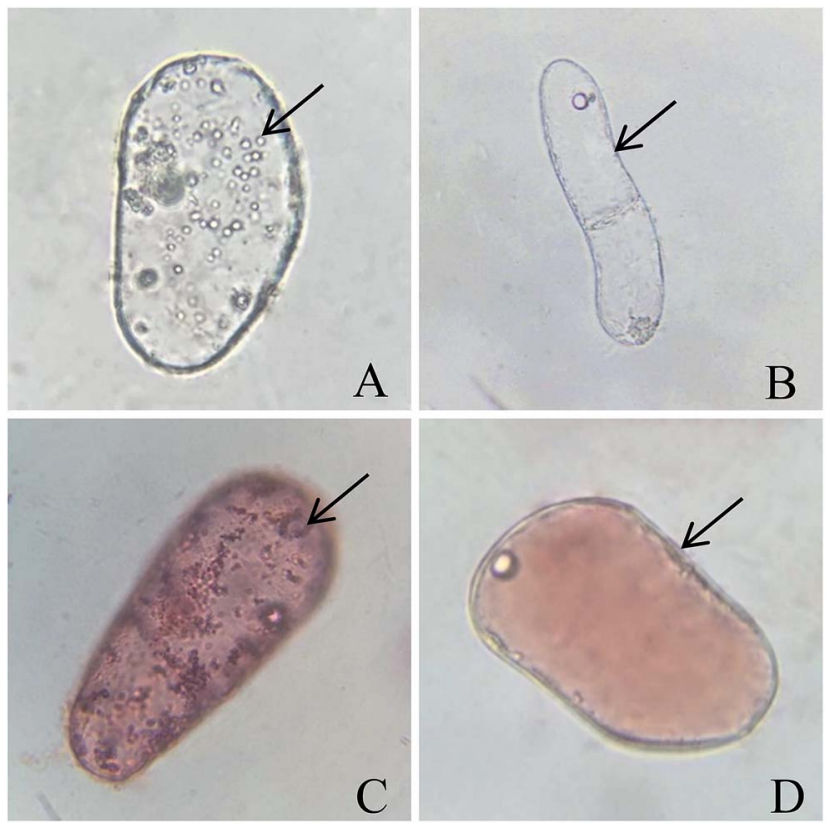

Fig. 2 Micrographs of CMCs and DDCs from C. acuminata. The vacuole is indicated using a black arrow. Micrographs of single CMC (A) and DDC (B). Micrographs of single CMC (C) and DDC (D) after stained with neutral red.

(40-200 Gy), and reached 72.1\% with 200 Gy. However, DDCs cell death reached only $31.1 \%$ after exposure to 200 Gy of $\gamma$ irradiation. These results suggest that CMCs were significantly more sensitive to $\gamma$-irradiation than DDCs.

CMCs and DDCs were incubated with different concentration zeocin for $24 \mathrm{~h}$ in the dark, and then photographed (Fig. 4A1-A3 and B1-B3). The cell death rate of CMCs was increased significantly $(P<0.05)$ compared with that of DDCs treated with different concentrations of zeocin, as shown in Fig. 5C. After incubation in medium containing $40 \mu \mathrm{g} \mathrm{mL}$ zeocin for $24 \mathrm{~h}$, CMCs had a high death rate of $80.5 \%$. The cell death rate of CMCs had little increase at doses of 80-200 $\mu \mathrm{g}$ $\mathrm{mL}^{-1}$ zeocin, and reached $82.8 \%$ with $200 \mu \mathrm{g} \mathrm{mL}{ }^{-1}$. However, the maximum DDCs death rate was $35.1 \%$ after incubation with different concentrations of zeocin for $24 \mathrm{~h}$. These results suggest that CMCs were particularly hypersensitive to zeocin, whereas DDCs were not.

The morphologic and physiologic characteristics of CMCs, including microscopic analysis revealing small, abundant vacuoles, hypersensitivity to $\gamma$-irradiation and the radiomimetic drug zeocin, and increased cell death rates, have been analyzed in a variety of plant species. ${ }^{\mathbf{1 2 - 1 6}}$ The above traits of CMCs from C. acuminate are completely consistent with the CMCs reported previously.

\section{Optimization of the growth medium for CMCs and DDCs}

To optimize the growth medium, CMCs and DDCs were subcultured in $\mathrm{MS}, \mathrm{B}_{5}, \mathrm{BDS}$, or $\mathrm{SH}$ medium supplemented with $0.1 \mathrm{mg} \mathrm{L}^{-1}$ 2,4-D, $0.1 \mathrm{mg} \mathrm{L}^{-1}$ 6-benzyl aminopurine (6-BA), and $30 \mathrm{~g} \mathrm{~L}^{-1}$ sucrose. After 36 days, the dry weight of the cultures was used to establish growth curves, which were made up of the lag phase, the logarithmic phase, and the plateau phase. For CMCs, $\mathrm{B}_{5}$ was obviously the best choice of growth medium. The logarithmic phase of cultures occurred at days 12-24. Thereafter, the growth of the cultures entered the plateau phase. Ultimately, the cultures had a total DW of $5.0 \pm 0.8 \mathrm{~g} \mathrm{~L}^{-1}$ in the plateau phase, which was an approximate 6.3-fold increase compared with the DW at day 3 (Fig. 5A). For DDCs, cultures grown in $\mathrm{SH}$ medium had a better growth state, with a logarithmic phase at days 9-15 (Fig. 5B). However, the growth of DDCs decreased slowly after subculture some times. As a result, $\mathrm{B}_{5}$ medium was selected as the growth medium for DDCs. Ultimately, $\mathrm{B}_{5}$ medium supplemented with $1.0 \mathrm{mg} \mathrm{L}^{-1} \mathrm{NAA}$, $0.5 \mathrm{mg} \mathrm{L}^{-1}$ 2,4-D, $0.05 \mathrm{mg} \mathrm{L}^{-1} \mathrm{KT}$, and $30 \mathrm{~g} \mathrm{~L}^{-1}$ sucrose was used as the subculture medium for both CMCs and DDCs, and the cells were subcultured every 21 days.

\section{The growth kinetics of CMCs and DDCs}

According to the sucrose, $\mathrm{PO}_{4}{ }^{3-}, \mathrm{NH}_{4}{ }^{+}$and $\mathrm{NO}_{3}{ }^{-}$content in the media and $\mathrm{pH}$ of media, additional information was obtained about the CMCs and DDCs from C. acuminata. The consumption of sucrose was consistent with the logarithmic phase of the cultures. Sucrose, which is used as the energy source for cell division, was quickly consumed when the cultures were about to enter the logarithmic phase after 6 days in culture in both CMCs and DDCs (Fig. 5C). Sucrose was consumed slowly when the cultures entered the plateau phase. Phosphorus is a constituent of membrane phospholipids and nucleic acids, and was consumed quickly when CMCs and DDCs were subcultured for 6-15 days (Fig. 5D). The pH of the media fluctuated between 5.0-7.0 during the growth period in both CMCs and DDCs (Fig. 5D). Ammonium and nitrate were immediately utilized to synthesis proteins when CMCs and DDCs were cultured (Fig. 5E). The nitrate content in the medium was stable after CMCs and DDCs were cultured for 21 days. However, ammonium levels were ultimately almost exhausted at the end of the plateau phase in both CMCs and DDCs. This demonstrates that the subculture media had a good buffering capacity and satisfied the demands for sucrose, phosphorus, ammonium, and nitrate during the growth of CMCs and DDCs.

\section{Quantification of CPT and HCPT}

CPT and HCPT have anti-cancer activity, and are used for the treatment of a diverse range of cancers. ${ }^{2,3}$ CPT and HCPT were detected in both CMCs and DDCs from C. acuminata. The concentration of CPT in CMCs $\left(2.55 \mu \mathrm{g} \mathrm{g}^{-1} \mathrm{DW}\right)$ was 1.55 -fold higher than that in DDCs $\left(1.65 \mu \mathrm{g} \mathrm{g}^{-1} \mathrm{DW}\right)$. Similarly, the concentration of HCPT in CMCs (25.59 $\left.\mu \mathrm{g} \mathrm{g}^{-1} \mathrm{DW}\right)$ was 2.50fold higher than that in DDCs $\left(10.22 \mu \mathrm{g} \mathrm{g}^{-1} \mathrm{DW}\right)$. Significantly, CMCs from C. acuminata were capable of yielding more CPT and HCPT than DDCs.

\section{Expression of CPT and HCPT biosynthesis genes}

The CPT and HPCT biosynthesis pathway in C. acuminata is a very complex process that involves many vital steps that are controlled by the key enzymes isopentenyl diphosphate 

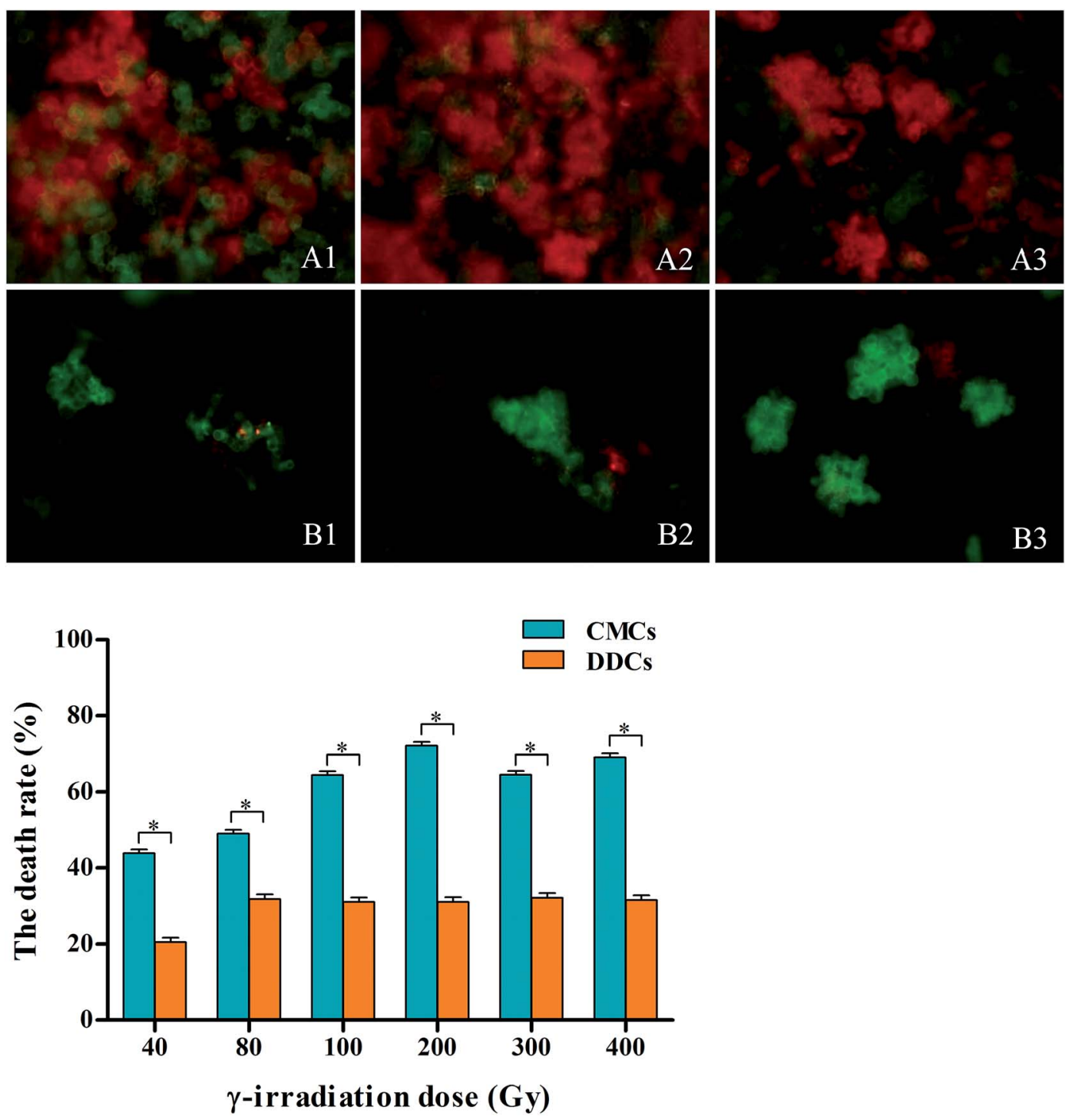

C

Fig. 3 Effects of $\gamma$-irradiation on the death of C. acuminata CMCs and DDCs. Values are expressed as means \pm SDs $(n=3)$, $* P<0.05$. Micrographs of CMCs (A1-A3) and DDCs (B1-B3) incubated for $24 \mathrm{~h}$ in the dark after exposure to $\gamma$-irradiation. Bright green fluorescence indicates live cells, and bright red fluorescence indicates dead cells. (C) The death rates of CMCs and DDCs after exposure to different dose of $\gamma$ irradiation and incubation for $24 \mathrm{~h}$.

isomerase (IPI), geraniol-10-hydroxylase (G10H), anthranilate synthase (ASA), tryptophan synthase (TSB), tryptophan decarboxylase (TDC), strictosidine synthase (STR), and 3-hydroxy-3methylglutaryl-CoA reductase (HMGR) (Fig. 6). The genes encoding the above enzymes have all been isolated from C. acuminata. ${ }^{17-23}$ To gain insight into the molecular events underlying the significant difference between CPT and HCPT concentrations in CMCs and DDCs, the transcriptional expression of IPI, G1OH, ASA1, TSB, TDC1, TDC2, STR, HMGR2 and HMGR3 was monitored using qRT-PCR (Fig. 7). The relative expression levels of $H M G R 2, H M G R 3, T S B, T D C 1, T D C 2$, and $S T R$ were normalized to the reference housekeeping gene actin as an internal standard. In contrast, the relative expression levels of IPI, G1OH, and ASA1 were normalized to the reference housekeeping gene $18 S$ as the internal standard. The expression levels of IPI, G1OH, ASA1, TSB, TDC1, TDC2, STR, HMGR2, and HMGR3 were significantly different between CMCs and DDCs $(P<0.01, P<0.001, P<0.001, P<0.01, P<0.05, P<0.05, P<$ $0.001, P<0.01$, and $P<0.001$, respectively). The expression of IPI, ASA1, TSB and TDC1 were significantly higher in CMCs, with a 1.99-, 1.80-, 1.78-, and 1.47-fold increase compared with DDCs, respectively. The expression levels of $T D C 2$ and $G 10 H$ were 4.56and 4.07-fold higher in CMCs compared with DDCs, respectively. In particular, the expression of STR was 8.86-fold higher in CMCs than DDCs. In contrast, HMGR2 and HMGR3 levels were 2.51- and 4.28-fold higher in DDCs compared with CMCs, respectively. 

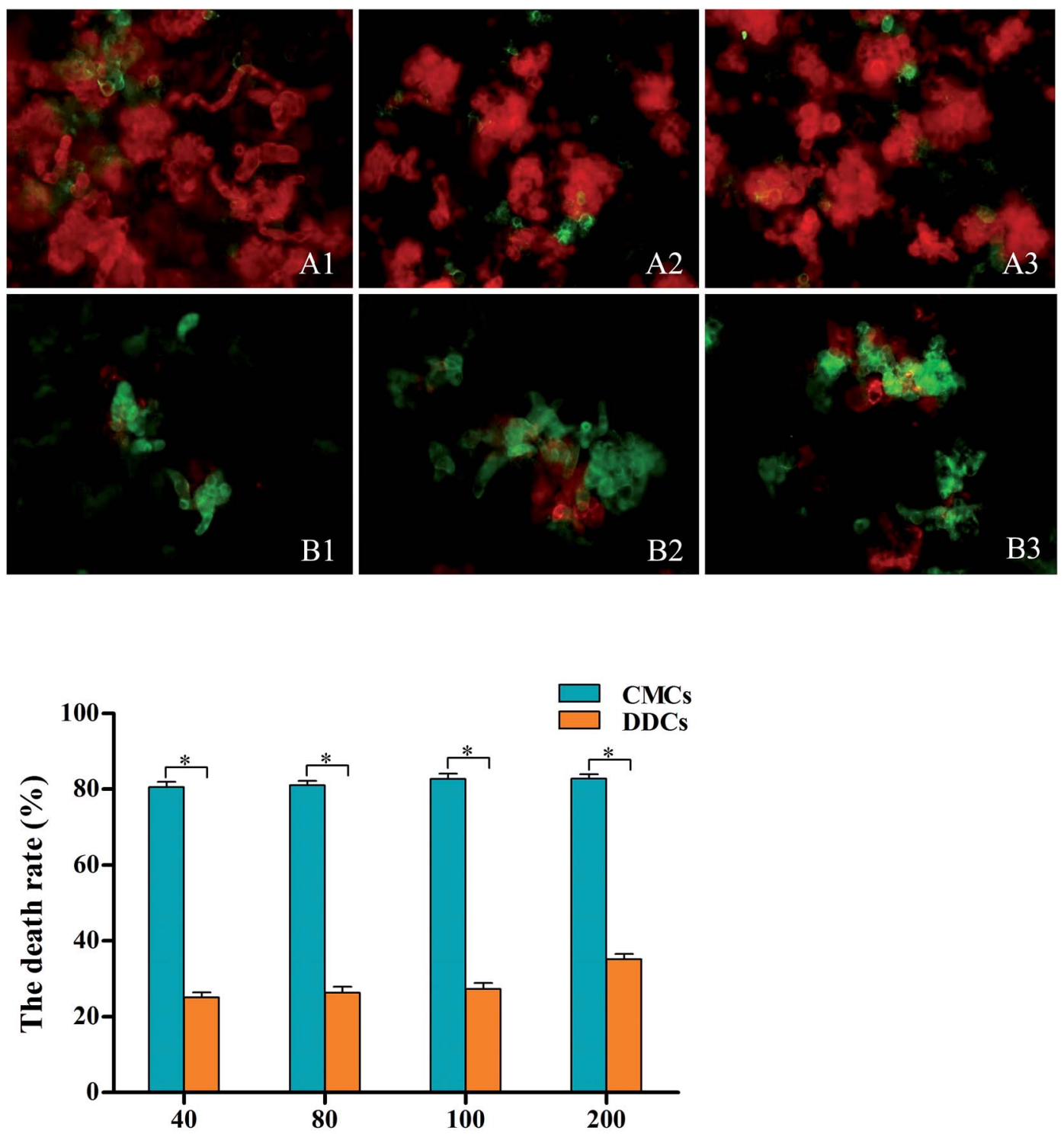

The concentration of zeocin in medium $(\mu \mathrm{g} / \mathrm{mL})$

C

Fig. 4 Effects of zeocin on the death of C. acuminata CMCs and DDCs. Values are expressed as means \pm SDs $(n=3)$, $* P<0.05$. Micrographs of CMCs (A1-A3) and DDCs (B1-B3) after incubation in medium containing zeocin for $24 \mathrm{~h}$ in the dark. (C) The death rates of CMCs and DDCs after incubation in medium containing different concentration of zeocin for $24 \mathrm{~h}$.

Obviously, the transcriptional expression of IPI, G10H, ASA1, $T S B, T D C 1, T D C 2$ and $S T R$ in CMCs was remarkably upregulated, whereas HMGR2 and HMGR3 were not. The effects of the expressions of the above genes on terpenoid synthesis have been reported. For example, Kajiwara et al. reported that expression of IPI could enhance isoprenoid biosynthesis in Escherichia coli. ${ }^{24}$ The co-overexpression of $G 10 H$ and 1-deoxy-Dxylulose synthase (DXS) or ASA and DXS resulted in an increase in several TIAs in Catharanthus roseus hairy roots. ${ }^{25}$ It was also reported that the $\mathrm{G} 10 \mathrm{H}$ activity was correlated to the accumulation of TIAs in C. roseus. ${ }^{26}$ The patterns of $S T R$ expression roughly correlated with CPT accumulation in some organs of Ophiorrhiza pumila. $^{27}$ HMGR catalyzes the conversion of 3-hydroxy-methylglutaryl-CoA (HMG-CoA) to mevalonate (MVA), and this conversion is the first key step in the MVA pathway in plants. In addition, the $H M G R$ gene plays a key role in the biosynthesis of triterpenoid in many medical plants, and its overexpression can improve the production of triterpenoid..$^{28-30}$ We speculate that the high accumulation of CPT and HCPT in CMCs could likely be attributed to the effects of the upregulation of the above mentioned seven genes, which offset the downregulation of $H M G R 2$ and $H M G R 3$. 


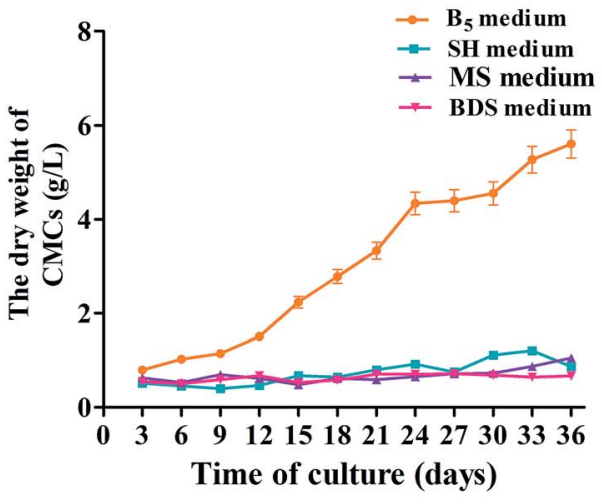

A

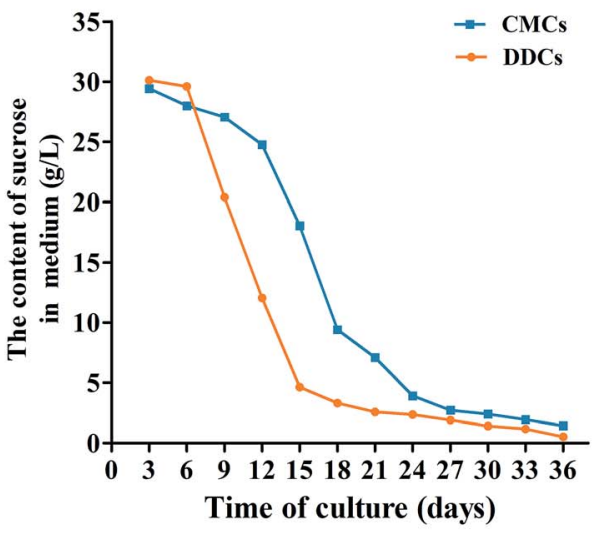

C

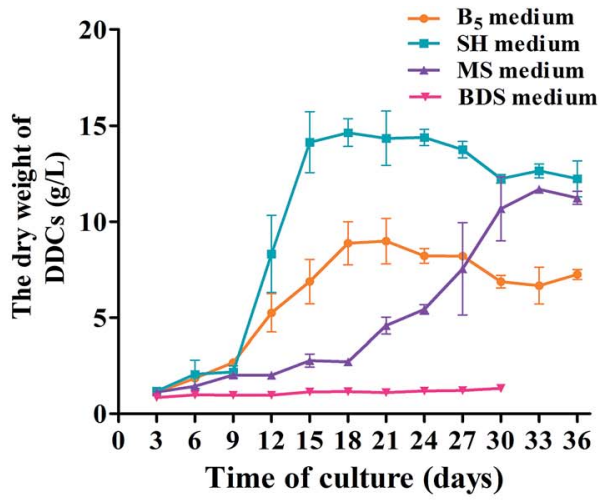

B

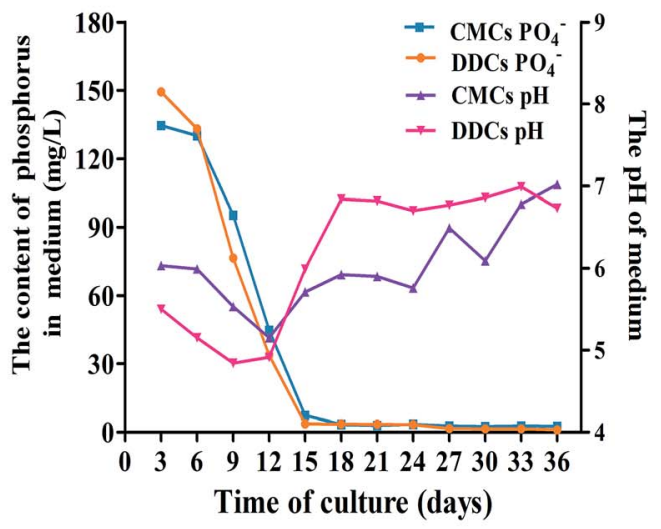

D

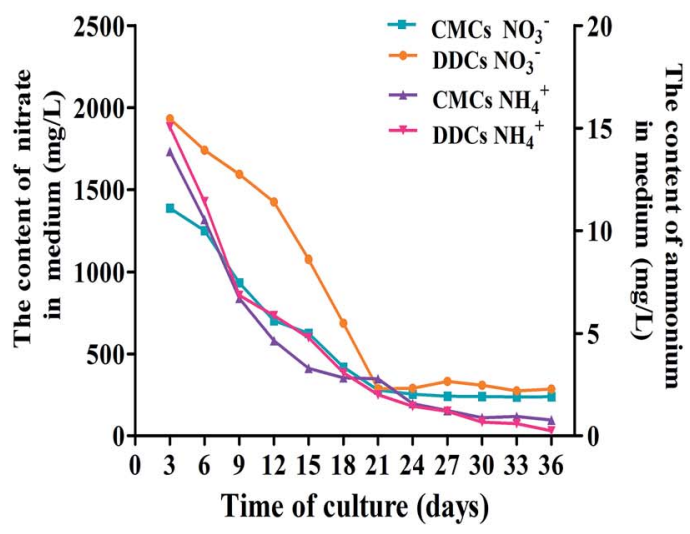

$\mathbf{E}$

Fig. 5 The growth curves and kinetics of CMCs and DDCs from C. acuminata. Values are expressed as means \pm SDs ( $n=3$ ). The dry weight of CMCs (A) and DDCs (B) from C. acuminata on MS, $\mathrm{B}_{5}$, BDS, or SH medium. (C) Time course of the sucrose content in medium containing CMCs and DDCs. (D) Time course of the phosphorus content and $\mathrm{pH}$ of medium containing CMCs and DDCs. (E) Time course of the nitrate and ammonium content of medium containing CMCs and DDCs.

\section{Experimental}

\section{Induction of CMCs and DDCs}

The stems and leaves of $C$. acuminata were obtained from Yaowang Mountain, Guangzhou University of Chinese Medicine, Guangzhou, China. The stems were washed immediately in running tap water for $30 \mathrm{~min}$, and the surfaces were disinfected with $75 \%$ ethanol for $1 \mathrm{~min}$. They were then washed with sterilized distilled water $\left(\mathrm{dH}_{2} \mathrm{O}\right)$, before $1 \% \mathrm{NaOCl}$ and a drop of Tween-20 were added, and mixed vigorously for $4 \mathrm{~min}$. After an additional wash with $\mathrm{dH}_{2} \mathrm{O}, 0.1 \% \mathrm{HgCl}_{2}$ and a drop of Tween-20 were added, and the stems were mixed vigorously for $4 \mathrm{~min}$ and washed with $\mathrm{dH}_{2} \mathrm{O}$. The leaves were sterilized as described above, but were maintained in $\mathrm{HgCl}_{2}$ for only $2 \mathrm{~min}$ due to their tender nature. 


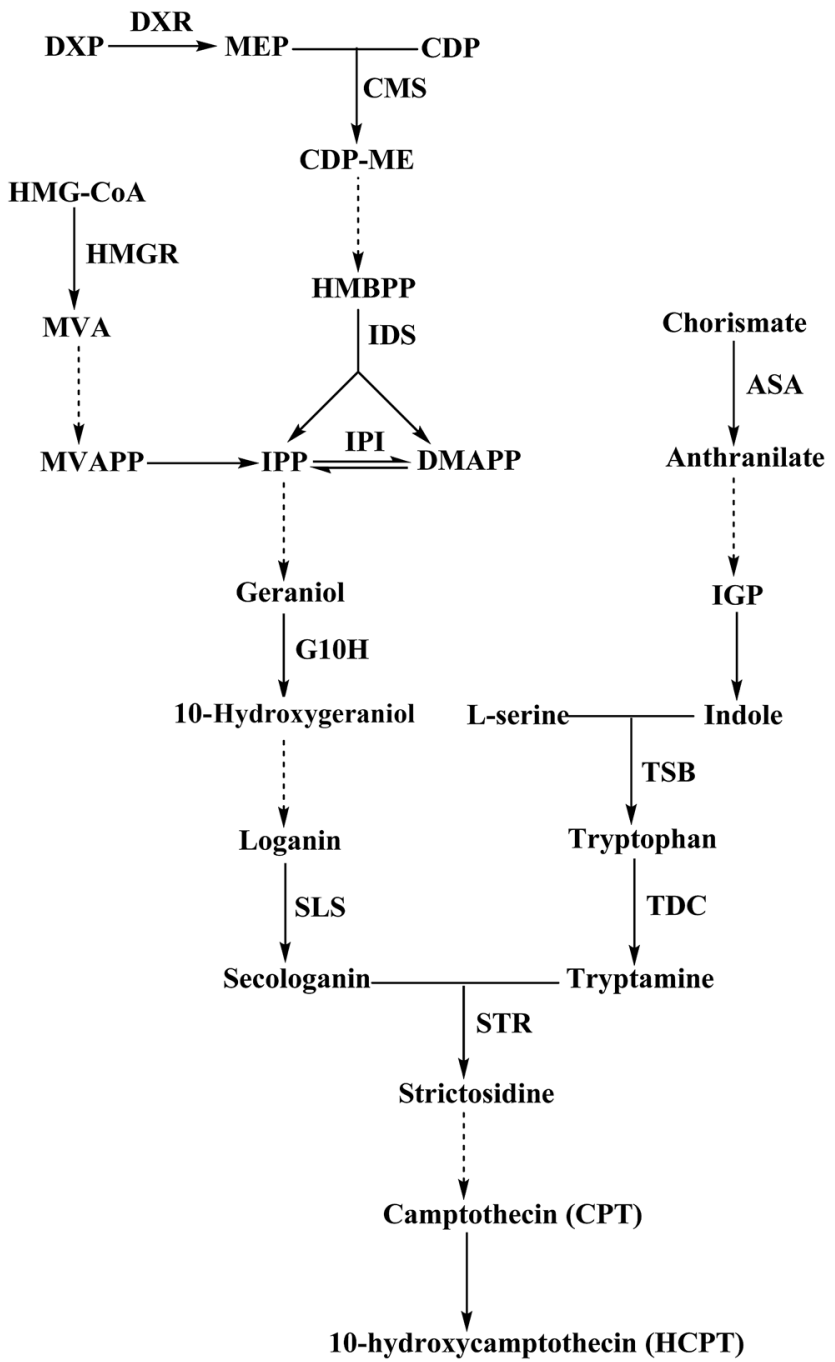

Fig. 6 Biosynthesis pathway of CPT and HCPT. Dotted line arrows indicated the involvement of multiple enzymatic steps. DXR, DXP reductoisomerase; CMS, 4-(cytidine 5-diphospho)-2-C-methylerythritol synthase; IDS, IPP/DMAPP synthase; IPI, IPP isomerase; HMGR, 3-hydroxy-3-methylglutaryl-CoA reductase; $\mathrm{G1OH}$, geraniol-10hydroxylase; SLS, secologanin synthetase; ASA, anthranilic acid synthetase; TSB, tryptophan synthase beta; TDC, tryptophan decarboxylase; STR, strictosidine synthase.

For CMCs, stems were cut into $1 \mathrm{~cm}$ (length) segments. The cambium, phloem, cortex, and epidermal tissue were peeled off from the xylem and laid on $100 \mathrm{~mL}$ Erlenmeyer flasks containing $40 \mathrm{~mL}$ of MS medium supplemented with $0.1 \mathrm{mg} \mathrm{L}^{-1}$ 2,4-D, $0.1 \mathrm{mg} \mathrm{L}^{-1} \mathrm{KT}, 0.1 \mathrm{mg} \mathrm{L}^{-1} \mathrm{NAA}$, and $30 \mathrm{~g} \mathrm{~L}^{-1}$ sucrose. The $\mathrm{pH}$ of the medium was adjusted to 5.75 before the addition of $7.5 \mathrm{~g} \mathrm{~L}^{-1}$ agar, which was followed by sterilization at $121^{\circ} \mathrm{C}$ for $20 \mathrm{~min}$. The explants were cultured at $25 \pm 1{ }^{\circ} \mathrm{C}$ in the dark. For DDCs, leaves were cut and laid on MS medium as described above.

\section{Identification of CMCs and DDCs}

Micrographs of CMCs and DDCs. DDCs and CMCs were treated with $0.1 \%$ neutral red (Aladdin, Shanghai, China) for 10 min, rinsed with phosphate buffer $(\mathrm{pH}$ 6.5) several times,

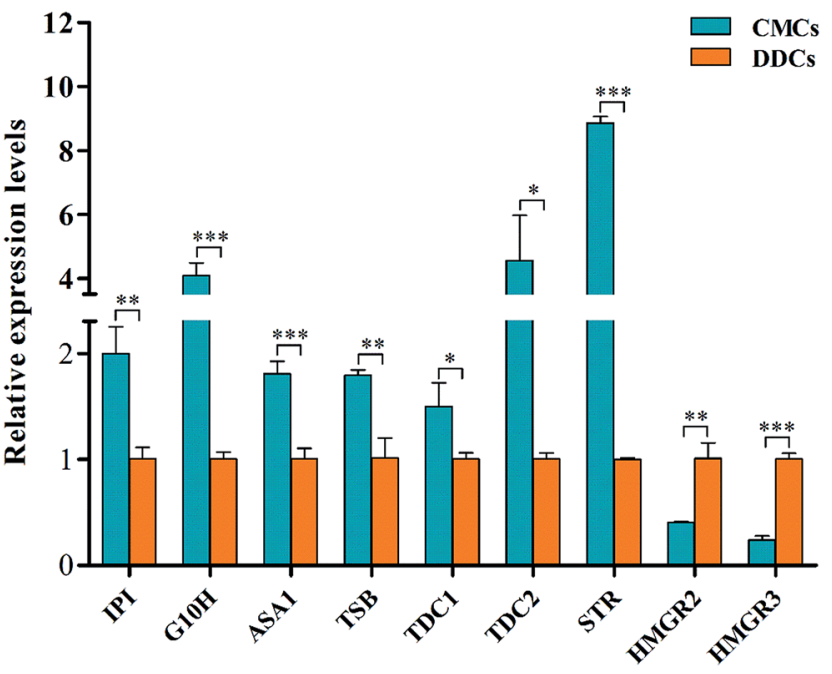

Fig. 7 The relative expression levels of IPI, G1OH, ASA1, TSB, TDC1, TDC2, STR, HMGR2, and HMGR3 in CMCs and DDCs. Three replicates per sample were used for qRT-PCR, and the values are expressed as means \pm SDs $(n=3)$. $* P<0.05, * * P<0.01$, and $* * * P<0.001$.

and then observed under an optical microscope (ML32, MSHOT, China).

Influence of $\gamma$-irradiation and zeocin on CMCs and DDCs. CMCs and DDCs suspension cells were obtained after culture for 15 days. For $\gamma$-irradiation treatments, cultures were irradiated with 40, 80, 100, 200, 300, and 400 Gy at a dose rate of 2.67 Gy $\min ^{-1}$, and placed back in culture at $25{ }^{\circ} \mathrm{C}$ in the dark for $24 \mathrm{~h}$. For zeocin treatments, cultures were placed in medium containing 40, 80, 120, and $200 \mu \mathrm{g} \mathrm{mL} \mathrm{m}^{-1}$ zeocin (Invitrogen, Carlsbad, USA), and agitated at $110 \mathrm{rpm}$ at $25{ }^{\circ} \mathrm{C}$ in the dark for $24 \mathrm{~h}$. To detect cell death, cells were treated with a fluorescent dye containing $0.1 \%$ fluorescein diacetate (FDA; Sigma, USA) and $0.1 \%$ Evan's blue (EB; Sigma) for $10 \mathrm{~min}$, rinsed with phosphate buffer several times, and transferred to a Petri dish. Then, FDA and EB were excited using red and blue ion lasers under a fluorescent inverted microscope (BX43, Olympus, Japan) as previously described. ${ }^{\mathbf{1 4}}$ The number of stained living (green) and dead (red) CMCs and DDCs was counted and the cells were photographed under the same view using a fluorescent inverted microscope. Three different fields were analyzed in each group.

\section{Optimizing the growth medium for CMCs and DDCs}

CMCs and DDCs were inoculated into $250 \mathrm{~mL}$ Erlenmeyer flasks containing $80 \mathrm{~mL}$ of $\mathrm{MS}, \mathrm{B}_{5}$, BDS, or $\mathrm{SH}$ medium supplemented with $0.1 \mathrm{mg} \mathrm{L}^{-1}$ 2,4-D, $0.1 \mathrm{mg} \mathrm{L}^{-1}$ 6-BA, and $30 \mathrm{~g} \mathrm{~L}^{-1}$ sucrose. The Erlenmeyer flasks were agitated at $110 \mathrm{rpm}$ and $25^{\circ} \mathrm{C}$ in the dark. Cultures were assessed every 3 days to day 36 to establish growth curves. All cultures were analyzed in triplicate, and the values are expressed as means \pm SDs.

\section{The growth kinetics of CMCs and DDCs}

According to the CMCs and DDCs growth curves obtained in different media described in Section 2.3, both CMCs and DDCs 
were inoculated into $250 \mathrm{~mL}$ Erlenmeyer flasks containing 80 $\mathrm{mL} \mathrm{B}_{5}$ medium supplemented with $0.1 \mathrm{mg} \mathrm{L}^{-1} 2,4-\mathrm{D}, 0.1 \mathrm{mg} \mathrm{L}^{-1}$ 6-BA, and $30 \mathrm{~g} \mathrm{~L}^{-1}$ sucrose. The Erlenmeyer flasks were agitated at $110 \mathrm{rpm}$ and $25{ }^{\circ} \mathrm{C}$ in the dark. Liquid cultures were removed every 3 days to day 36 to study the growth kinetics of CMCs and DDCs. After the liquid media were filtered, the sucrose, $\mathrm{NH}_{4}{ }^{+}$, $\mathrm{NO}_{3}{ }^{-}$and $\mathrm{PO}_{4}{ }^{3-}$ contents in the filtrate were measured using phenol-sulfuric acid, phenol-hypochlorite, salicylic acidsulfuric acid, and phosphomolybdate blue methods, respectively, as reported previously. ${ }^{31-34}$ The $\mathrm{pH}$ of the filtrates was also measured using a pH meter (FE20, METTLER TOLEDO, Switzerland).

\section{Extraction and quantification of CPT and HCPT}

After culture for 10 days in the dark, CMCs and DDCs cultures were dried at $55{ }^{\circ} \mathrm{C}$ and crushed separately. One gram of the above dried cultures was soaked in $50 \mathrm{~mL}$ methanol for $12 \mathrm{~h}$, followed by ultrasonic extraction for $2.5 \mathrm{~h}$. The methanol extracts were centrifuged at $12000 \mathrm{rpm}$ for $10 \mathrm{~min}$ and the supernatants were collected. Then, the residues were extracted with an equal volume methanol twice. The extracts were concentrated and evaporated to dryness. Next, $50 \mathrm{~mL}$ of water was added and three extractions were performed using an equal volume of chloroform. The chloroform extracts were evaporated to dryness, dissolved in $3 \mathrm{~mL}$ methanol, filtered using a $0.45 \mu \mathrm{m}$ Acrodisc syringe filter, and analyzed by HPLC. HPLC was performed using a $\mathrm{C}_{18}$ column $(250 \times 4.6 \mathrm{~mm}, 5 \mu \mathrm{m}$; Phenomenex Synergi, USA) with an Agilent 1260 HPLC system (Agilent Technologies, Santa Clara, CA, USA) equipped with an ultraviolet detector. The mobile phase consisted of a mixture of $\mathrm{MeOH} /$ $\mathrm{H}_{2} \mathrm{O}(50: 50, \mathrm{v} / \mathrm{v})$. The flow rate was maintained at $1.0 \mathrm{~mL}$ $\min ^{-1}$, the injection volume was $10 \mu \mathrm{L}$, the detection wavelength was $254 \mathrm{~nm}$, and the column was maintained at $25{ }^{\circ} \mathrm{C}$. The concentrations of CPT and HCPT were determined using standard curves. The standard curves were as follows:

$$
\begin{gathered}
\text { CPT, } Y=4202.2 X-0.9626\left(R^{2}=0.9999\right) \\
\text { HCPT, } Y=708.86 X+5.5547\left(R^{2}=0.9992\right),
\end{gathered}
$$

where $Y$ indicates the peak area of CPT or HCPT and $X$ indicates the concentration of CPT or HCPT.

\section{Expression of CPT and HCPT biosynthesis genes}

Plant materials. CMCs and DDCs were separately cultured in solid $\mathrm{B}_{5}$ medium supplemented with $1.0 \mathrm{mg} \mathrm{L}^{-1} \mathrm{NAA}, 0.5 \mathrm{mg}$ $\mathrm{L}^{-1}$ 2,4-D, $0.05 \mathrm{mg} \mathrm{L}^{-1} \mathrm{KT}, 30 \mathrm{~g} \mathrm{~L}^{-1}$ sucrose, and $7.5 \mathrm{~g} \mathrm{~L}^{-1}$ agar at $25{ }^{\circ} \mathrm{C}$ in the dark for 10 days for total RNA isolation.

RNA isolation and cDNA synthesis. CMCs and DDCs cultures were ground with a mortar and pestle in liquid nitrogen. Next, $1 \mathrm{~mL}$ of Trizol (TaKaRa, Dalian, China) was added to the ground samples, mixed very well, and allowed to settle for $5 \mathrm{~min}$. Then, $0.2 \mathrm{~mL}$ of chloroform was added, mixed vigorously for $15 \mathrm{~s}$, settled for $3 \mathrm{~min}$, and centrifuged for $10 \mathrm{~min}$ at $12000 \mathrm{rpm}$ at $4{ }^{\circ} \mathrm{C}$. The supernatants were transferred to new tubes; an equal volume of isopropyl alcohol was added, mixed very well, settled

for $20 \mathrm{~min}$, and centrifuged for $10 \mathrm{~min}$ at $12000 \mathrm{rpm}$ and $4{ }^{\circ} \mathrm{C}$. After removing the supernatant, the precipitates were dissolved in $1 \mathrm{~mL}$ of a $3: 1$ ratio of alcohol : DEPC, washed, and centrifuged for $5 \mathrm{~min}$ at $12000 \mathrm{rpm}$ at $4{ }^{\circ} \mathrm{C}$. After removing the supernatant the RNA pellet was air-dried at $25{ }^{\circ} \mathrm{C}$, verified by running on an agarose gel, dissolved in $30 \mu \mathrm{L}$ of DEPC-treated $\mathrm{ddH}_{2} \mathrm{O}$, and stored at $-80{ }^{\circ} \mathrm{C}$. For cDNA synthesis, $1 \mu \mathrm{g}$ of total RNA was used for reverse transcription using Bestar qPCR RT Kit (DBI, Germany) according to the manufacturer's instructions. Twenty microliters of the cDNA was used as a template for qRT-PCR.

qRT-PCR. Based on the published gene sequences of IPI, G10H, ASA1, TSB, TDC1, TDC2, STR, HMGR2, and HMGR3 (GenBank accession numbers DQ839416.1, JF508378.1, AY753655.1, AF042321.1, U73656.1, U73657.2, JF508375.1, U72146.1, and U72145.1, respectively), qRT-PCR primers were designed using Primer 5.0 (Table 1). Gene expression was determined using the relative quantification method with actin (actin-F, 5'-GTGACAATGGAACTGGAATGG-3'; actin-R, 5' AGACGGAGGATAGCGTGAGG- $3^{\prime}$ ) and $18 \mathrm{~S}$ (18S-F, $5^{\prime}$-ATGATAACTCGACGGATCGC-3' ${ }^{\prime}$ 18S-R, 5'-CTTGGATGTGGTAGCCGTTT- $3^{\prime}$ ) as the internal references. For quantification of the standard, the PCR products amplified from cDNA were purified, and their concentration was measured to calculate the number of cDNA copies. qRT-PCR reactions were performed in a $20 \mu \mathrm{L}$ reaction mixture containing $2 \mu \mathrm{L}$ template cDNA, $10 \mu \mathrm{L}$ SYBR Green qPCR Master Mix (DBI, Germany), $0.5 \mu \mathrm{L}$ of each specific primer $(10 \mu \mathrm{m})$, and $\mathrm{dd}_{2} \mathrm{O}$. The thermal cycling conditions were as follows: $95{ }^{\circ} \mathrm{C}$ for $2 \mathrm{~min}$, followed by 40 cycles of $94{ }^{\circ} \mathrm{C}$ for $20 \mathrm{~s}, 58{ }^{\circ} \mathrm{C}$ for $20 \mathrm{~s}$, and $72{ }^{\circ} \mathrm{C}$ for $20 \mathrm{~s}$. The PCR reactions were performed in a Stratagene Mx3000P Real time PCR system (Agilent Technologies, Santa Clara, CA, USA), and the PCR products were analyzed using Bio-Rad CFX Manager 2.0 software. Three replicates per sample were used for the qRT-PCR analysis, and values are expressed as means \pm SDs.

\begin{tabular}{|c|c|c|}
\hline $\begin{array}{l}\text { Gene } \\
\text { names }\end{array}$ & Primer sequence $\left(5^{\prime}\right.$ to $\left.3^{\prime}\right)$ & $\begin{array}{l}\text { Product } \\
\text { sizes (bp) }\end{array}$ \\
\hline \multirow[t]{2}{*}{ IPI } & Forward: AAGGTAACATTCCCTCTGGC & \multirow[t]{2}{*}{114} \\
\hline & Reverse: CTTCCTTTGTGCAGCATTTC & \\
\hline \multirow[t]{2}{*}{$G 10 H$} & Forward: ATGGATGTATTTATTGCTGCC & \multirow[t]{2}{*}{141} \\
\hline & Reverse: TTCTACTAACTTGCCTTTGCC & \\
\hline \multirow[t]{2}{*}{ ASA1 } & Forward: GGAATGAAACGCTTGGAAAT & \multirow[t]{2}{*}{111} \\
\hline & Reverse: CTTCAAAGGAGGACCGTAATG & \\
\hline \multirow[t]{2}{*}{$T S B$} & Forward: CTGCACTATCGCCAGAGAGAT & \multirow[t]{2}{*}{175} \\
\hline & Reverse: TTGGTCTCCAGATAGAGATCG & \\
\hline \multirow[t]{2}{*}{$T D C 1$} & Forward: ACTGAATCTCCGGCATCCGTT & \multirow[t]{2}{*}{208} \\
\hline & Reverse: TCAGAATGCTCTCGAATGGCT & \\
\hline \multirow[t]{2}{*}{$T D C 2$} & Forward: AGCGGA ACTTGAGCTGGAGAT & \multirow[t]{2}{*}{353} \\
\hline & Reverse: CTGCCACGTCAGCTTCTATCT & \\
\hline \multirow[t]{2}{*}{$S T R$} & Forward: TACCTTTGACTTGCCCCTTG & \multirow[t]{2}{*}{168} \\
\hline & Reverse: ATTGGTGCTAAGAATGTGTTGTT & \\
\hline \multirow[t]{2}{*}{$H M G R 2$} & Forward: AGACAAGAAGCCAGCAGCAGT & \multirow[t]{2}{*}{182} \\
\hline & Reverse: TAAACCCACCAAGAGCACCAG & \\
\hline \multirow[t]{2}{*}{$H M G R 3$} & Forward: AGGAGGTTGTGAGGAAGGTGT & \multirow[t]{2}{*}{470} \\
\hline & Reverse: TGATCTGTTGTATTTCATGTGGC & \\
\hline
\end{tabular}

Table 1 The primers used for quantitative real-time PCR 


\section{Conclusions}

In the present study, CMCs of $C$. acuminata were isolated for the first time. The characteristic features of C. acuminate CMCs, including abundant and small vacuoles within each cell and hypersensitivity to $\gamma$-irradiation and zeocin, were consistent with CMCs reported previously. The growth curves and kinetics of CMCs and DDCs were detected simultaneously. Furthermore, HPLC analysis showed that the accumulation of CPT and HCPT was higher in CMCs than DDCs. Additionally, transcriptional analyses determined that the expression of IPI, G10H, ASA1, $T S B, T D C 1, T D C 2$, and $S T R$ was upregulated in CMCs compared with DDCs. The accumulation of CPT and HCPT in CMCs could likely be attributed to the upregulation of these seven genes which offset the effects of HMGR2 and HMGR3 downregulation. In conclusion, CMCs may be a good choice for obtaining CPT and HCPT, and this may offer an attractive and cost-effective option for the industrial production of CPT and HCPT.

\section{Acknowledgements}

This study was funded by the National Natural Science Foundation of China (No. 81673557, 81102779 and 81274060), the Guangdong Natural Science Foundation (No. 9451022401003453), the Pearl River S\&T Nova Program of Guangzhou (No. 2013J2200035), the Innovation Program of the University of Guangdong Province (No. 2014KTSCX118), the Science and Technology Program of Guangdong Province (No. 2014A050503067 and 2015A020211032) and the High-level Talents Program of the University of Guangdong Province.

\section{Notes and references}

1 M. E. Wall, M. C. Wani, C. E. Cook, K. H. Palmer, A. T. McPhail and G. A. Sim, J. Am. Chem. Soc., 1966, 88, 3888-3890.

2 Y.-H. Hsiang, R. Hertzberg, S. Hecht and L. F. Liu, J. Biol. Chem., 1985, 260, 14873-14878.

3 A. Lorence, F. Medina-Bolivar and C. L. Nessler, Plant Cell Rep., 2004, 22, 437-441.

4 V. J. Venditto and E. E. Simanek, Mol. Pharmaceutics, 2010, 7, 307-349.

5 M. López-Meyer, C. L. Nessler and T. D. McKnight, Planta Med., 1994, 60, 558-560.

6 K. Sakato, H. Tanaka, N. Mukai and M. Misawa, Agric. Biol. Chem., 1974, 38, 217-218.

7 A. J. V. Hengel, M. P. Harkes, H. J. Wichers, P. G. M. Hesselink and R. M. Buitelaar, Plant Cell, Tissue Organ Cult., 1992, 28, 11-18.

8 H. Wiedenfeld, M. Furmanowa, E. Roeder, J. Guzewska and W. Gustowski, Plant Cell, Tissue Organ Cult., 1997, 49, 213218.

9 G. Kai, X. Teng, L. Cui, S. Li, X. Hao, M. Shi and B. Yan, International Journal of Science, 2014, 3, 86-95.
10 X. Ni, S. Wen, W. Wang, X. Wang, H. Xu and G. Kai, J. Appl. Pharm. Sci., 2011, 01, 85-88.

11 W. Wang, Y. Lu, L. Li, J. Wang and G.-Y. Kai, Acta Bot. BorealiOccident. Sin., 2008, 28, 2416-2422.

12 C. Frankenstein, D. Eckstein and U. Schmitt, Dendrochronologia, 2005, 23, 57-62.

13 E.-K. Lee, Y.-W. Jin, J. H. Park, Y. M. Yoo, S. M. Hong, R. Amir, Z. Yan, E. Kwon, A. Elfick, S. Tomlinson, F. Halbritter, T. Waibel, B.-W. Yun and G. J. Loake, Nat. Biotechnol., 2010, 28, 1213-1217.

14 N. Fulcher and R. Sablowski, Proc. Natl. Acad. Sci. U. S. A., 2009, 106, 20984-20988.

15 B.-W. Yun, Z. Yan, R. Amir, S. Hong, Y.-W. Jin, E.-K. Lee and G. J. Loake, Biotechnol. Genet. Eng. Rev., 2012, 28, 47-60.

16 T. Furukawa, M. J. Curtis, C. M. Tominey, Y. H. Duong, B. W. L. Wilcox, D. Aggoune, J. B. Hays and A. B. Britt, DNA Repair, 2010, 9, 940-948.

17 R. J. Burnett, I. E. Maldonado-Mendoza, T. D. McKnight and C. L. Nessler, Plant Physiol., 1993, 103, 41-48.

18 M. López-Meyer and C. L. Nessler, Plant J., 1997, 11, 11671175.

19 H. Lu and T. D. McKnight, Plant Physiol., 1999, 120, 43-51.

20 H. Lu, E. Gorman and T. D. McKnight, Planta, 2005, 221, 352-360.

21 I. E. Maldonado-Mendoza, R. M. Vincent and C. L. Nessler, Plant Mol. Biol., 1997, 34, 781-790.

22 X. Pan, M. Chen, Y. Liu, Q. Wang, L. Zeng, L. Li and Z. Liao, DNA Sequence, 2008, 19, 98-105.

23 Y. Sun, H. Luo, Y. Li, C. Sun, J. Song, Y. Niu, Y. Zhu, L. Dong, A. Lv, E. Tramontano and S. Chen, BMC Genom., 2011, 12, 533-544.

24 S. Kajiwara, P. D. Fraser, K. Kondo and N. Misawa, Biochem. J., 1997, 324, 421-426.

25 C. A. M. Peebles, G. W. Sander, E. H. Hughes, R. Peacock, J. V. Shanks and K.-Y. San, Metab. Eng., 2011, 13, 234-240.

26 G. Collu, A. A. Garcia, R. V. D. Heijden and R. Verpoorte, Plant Sci., 2002, 162, 165-172.

27 Y. Yamazaki, A. Urano, H. Sudo, M. Kitajima, H. Takayama, M. Yamazaki, N. Aimi and K. Saito, Phytochemistry, 2003, 62, 461-470.

28 Q.-Y. Gai, J. Jiao, M. Luo, W. Wang, C.-J. Zhao, Y.-J. Fu and W. Ma, Ind. Crops Prod., 2016, 84, 350-357.

29 S. J. Hey, S. J. Powers, M. H. Beale, N. D. Hawkins, J. L. Ward and N. G. Halford, Plant Biotechnol. J., 2006, 4, 219-229.

30 Y.-K. Kim, J. K. Kim, Y. B. Kim, S. Lee, S.-U. Kim and S. U. Park, J. Agric. Food Chem., 2013, 61, 1928-1934.

31 P. S. Chen, T. Y. Toribara and H. Warner, Anal. Chem., 1956, 28, 1756-1758.

32 M. Dubois, K. A. Gilles, J. K. Hamilton, P. A. Rebers and F. Smith, Anal. Chem., 1956, 28, 350-356.

33 U. Hecht and H. Mohr, Physiol. Plant., 1990, 78, 379-387. 34 M. W. Weatherburn, Anal. Chem., 1967, 39, 971-974. 